\title{
A UTILIZAÇÃO DO MOODLE NO ENSINO DA MATEMÁTICA PARA ALUNOS COM DEFICIÊNCIA
}

\section{MOODLE PLATFORM'S USE IN MATHEMATICS TEACHING TO DISABLED STUDENTS}

Cláudia Ma Soares Rossi ${ }^{1}$
ORCID iD: $\underline{0000-0003-4257-0717}$

Daiane Beirigo Amorim ${ }^{2}$

ORCID iD: $\underline{0000-0002-8276-7437}$

Suyara Santos ${ }^{3}$

ORCID iD: 0000-0002-9455-1131

\begin{abstract}
RESUMO
O presente trabalho apresenta os resultados de uma experiência envolvendo o ambiente virtual de aprendizagem Moodle como recurso tecnológico no ensino de Matemática, para alunos com deficiência nos anos finais do Ensino Fundamental. De acordo com a bibliografia estudada, o ambiente virtual é uma ferramenta que torna o aluno ativo na busca do conhecimento, obtendo-se uma aprendizagem significativa. Com o intuito de mostrar o potencial da plataforma Moodle, este trabalho objetiva a criação de uma sala virtual com diversas atividades matemáticas, onde se desenvolviam os conteúdos vistos em sala de aula de uma forma diferenciada. Os resultados apontaram que o ambiente virtual contribuiu para a fixação dos conteúdos estudados e auxiliou na habilidade de abstração e raciocínio lógico dos alunos. Concluiu-se que os alunos com deficiência conseguem desenvolver suas habilidades matemáticas quando recebem o atendimento necessário e adaptação das atividades.
\end{abstract}

Palavras-chave: Deficiência. Inclusão. Matemática. Moodle.

\section{ABSTRACT/ RESUMEN}

This work presents the results of an experiment involving the virtual learning environment Moodle as a technological resource in Mathematics teaching for disabled students from the final years of Basic School. According to the bibliography studied, the virtual environment is a tool that makes the student active in the search for knowledge, obtaining meaningful learning. In order to show the potential of the Moodle platform, this work aims to create a virtual room with diverse mathematical activities, where the contents seen in the classroom were developed in a different way. The results showed that virtual environment contributed to consolidation of contents and helped the students' ability to abstraction and logics. It was concluded that disabled students can develop their mathematical skills when they get the necessary assistance and adaptated activities.

Keywords/Palabras clave: Disability. Inclusion. Mathematics. Moodle.

\footnotetext{
${ }^{1}$ Mestre em Educação pela Universidade Federal de Lavras (UFLA). Técnica em Assuntos Educacionais no IFMG, Arcos, Minas Gerais, Brasil. Endereço para correspondência: Avenida Laura Andrade, 700, Jardim Bela Vista, Arcos, Minas Gerais, Brasil, CEP: 35588-000. E-mail: claudia.rossi@ifmg.edu.br.

2 Pós-graduanda em Docência no Instituto Federal de Minas Gerais - IFMG Campus Arcos. Professora de Educação Básica na E.E.P.T.A.N, Cláudio, Minas Gerais, Brasil. Endereço para correspondência: Rua Cataguases, 75, Centro, Cláudio, Minas Gerais, Brasil, CEP: 35530-000. E-mail: daianedba@ hotmail.com.

${ }^{3}$ Pós-graduanda em Docência no Instituto Federal de Minas Gerais - IFMG Campus Arcos. Professora de Educação Básica na E.E.D.M.P, Arcos, Minas Gerais, Brasil. Endereço para correspondência: Rua Vera Cruz., 163, São Vicente, Arcos, Minas Gerais, Brasil, CEP: 35588-000. E-mail: suyara.santos@ hotmail.com.
} 


\section{INTRODUÇÃO}

A escola destaca-se perante a sociedade por ser lócus de aprendizagem, a qual se preocupa com a formação de seus alunos para que possam ser sujeitos críticos e participativos na sociedade.

De acordo com o censo escolar do Inep (Instituto Nacional de Estudos e Pesquisas Anísio Teixeira), o número de matrículas de alunos com deficiência em turmas regulares chegou a 1,3 milhão em 2019, aumentando 5,9\% comparado ao ano de 2018 , e $34,4 \%$ em relação a 2015, graças às leis que asseguram o direito desses indivíduos de estudar e conviver normalmente em sociedade. A Lei 7.853, de 24 de outubro de 1989, em seu Capítulo I, artigo $2^{\circ}$, trata desse direito quando decreta que:

Cabe aos órgãos e às entidades do Poder Público assegurar à pessoa portadora de deficiência o pleno exercício de seus direitos básicos, inclusive dos direitos à educação, à saúde, ao trabalho, ao desporto, ao turismo, ao lazer, à previdência social, à assistência social, ao transporte, à edificação pública, à habitação, à cultura, ao amparo à infância e à maternidade, e de outros que, decorrentes da Constituição e das leis, propiciem seu bem-estar pessoal, social e econômico.

Logo, foram necessárias diversas adequações a fim de atender as pessoas com deficiência. Dentre as mais importantes, podemos salientar as Salas de Recursos Multifuncionais, que, pelo Atendimento Educacional Especializado em ensino regular, oferecem métodos diferenciados e eficientes no desenvolvimento das habilidades desses alunos. Conforme Alves (2006) a Sala de Recursos Multifuncionais, "é um espaço organizado com materiais didáticos, pedagógicos, equipamentos e profissionais com formação para o atendimento às necessidades educacionais especiais, projetadas para oferecer suporte necessário às necessidades educacionais especiais dos alunos, favorecendo seu acesso ao conhecimento".

A escolha desta proposta justifica-se pela vivência das autoras com alunos deficientes. Em razão do contato diário com eles, percebemos suas dificuldades e anseios na aprendizagem dos conteúdos matemáticos. De acordo com Zwan (2016), verifica-se que vários estudos são realizados com propósito de contribuir para a qualidade do ensino desses alunos, discutindo-se estratégias, metodologias e recursos que possam auxiliar na sua melhoria.

Buscando utilizar as Salas de Recursos que se encontram disponíveis nas escolas, o objetivo deste trabalho é a criação de uma sala virtual na plataforma Moodle, de forma a tornar o conteúdo matemático mais compreensível e o ambiente para seu estudo mais inclusivo para 
alunos com deficiência.

O Ambiente Virtual de Aprendizagem (AVA) Moodle (Modular Object-Oriented Dynamic Learning Environment) é um software de construção colaborativa que propõe diversas formas de trabalhar de modo a facilitar o aprendizado do aluno.

Conforme Martins (2009) apud Castillo (2005),

O desenvolvimento do ambiente Moodle foi norteado por uma filosofia de aprendizagem - a teoria sócio construtivista (Social Constructivism). O sócio construtivismo defende a construção de idéias e conhecimentos em grupos sociais de forma colaborativa, uns para com os outros, criando assim uma cultura de compartilhamento de significados (CASTILLO, 2005).

Portanto, o Moodle se torna uma ferramenta para os alunos, promovendo situações de aprendizagem interativas e envolventes. $\mathrm{O}$ ambiente permite que o aluno seja autônomo e ativo, e, ao mesmo tempo, promove associação de significados e informações. Nesse ponto, o ensino tradicional - caracterizado por aulas expositivas em que o aluno é apenas um receptor do conhecimento - é superado quando o professor faz a ponte entre a ferramenta tecnológica e o conteúdo estudado.

No desenvolvimento das atividades desse trabalho, utilizaram-se os recursos disponíveis no Moodle, os quais proporcionam um ambiente de aprendizagem prazeroso e eficaz. Foram trabalhadas as quatro operações fundamentais com problemas contextualizados, geometria plana e espacial, unidades de medida e equação do $1^{\circ}$ grau.

A finalidade das tarefas propostas é auxiliar no aprofundamento dos conteúdos matemáticos já estudados nos anos finais do nível Fundamental, propiciando uma aprendizagem significativa e maior interesse nas aulas de matemática.

Durante a experiência, procurou-se identificar as habilidades dos alunos na realização das atividades e investigar como o Ambiente Virtual de Aprendizagem Moodle contribuiu para a aprendizagem desses alunos.

\section{A ESCOLA E A EDUCAÇÃO INCLUSIVA}

A escola pode ser considerada um espaço de aprendizagem que favorece relações humanas positivas, pois permite que os alunos possam conviver com as dificuldades, aprender a respeitar os colegas, compartilhar, conviver, lidar com hierarquias. Neste sentido, a escola participa diariamente da formação de cidadãos mais conscientes da importância que eles têm dentro da sociedade. 
O professor, diante disso, contribui significativamente para a formação de seus alunos, pois interfere na formação dos mesmos por meio de seu comportamento, de sua própria história de vida e da sua maneira de ser e de pensar.

A escola e os docentes devem aprender a conciliar suas condições às possibilidades e necessidades dos alunos. Portanto, a escola como um todo deve despender mais esforços, vontade e competência para sempre poder ajudar os alunos a aumentarem o potencial social e intelectual. Carmo (2015, p. 15) reforça a necessidade de se trabalhar a inclusão ao afirmar que:

A educação inclusiva possui a proposta de integrar ao ambiente escolar a valorização e aceitação das diferenças presente em cada indivíduo, tendo como desafio colocar em prática os preceitos da educação especial, que é o de transformar a escola em um espaço igualitário, onde todos os alunos possam estar incluídos no processo de ensino aprendizagem, seguindo o mesmo contexto escolar.

Logo, para receber um aluno com deficiência, a escola deve preparar não somente adaptações externas e infraestrutura, mas é necessário preparar também o professor, dando suporte e o capacitando para lidar com as necessidades desse aluno. Conforme documentos oficiais que orientam o ensino inclusivo, (BRASIL, 2006, p. 29):

[...] é necessário que os professores conheçam a diversidade e a complexidade dos diferentes tipos de deficiência física, para definir estratégias de ensino que desenvolvam o potencial do aluno. De acordo com a limitação física apresentada é necessário utilizar recursos didáticos e equipamentos especiais para a sua educação buscando viabilizar a participação do aluno nas situações prática vivenciadas no cotidiano escolar, para que o mesmo, com autonomia, possa otimizar suas potencialidades e transformar o ambiente em busca de uma melhor qualidade de vida.

Alunos com deficiência intelectual ou transtornos globais do desenvolvimento (TGD) também dependem da dedicação dos professores e devem receber tratamento especializado individualizado a fim de potencializar suas habilidades. São alunos que vão ter dificuldades para se comunicar, socializar e aprender algo novo, todavia essa condição "não é considerada uma doença ou um transtorno psiquiátrico, e sim um ou mais fatores que causam prejuízo das funções cognitivas que acompanham o desenvolvimento diferente do cérebro". (HONORA \& FRIZANCO, 2008, p. 103).

Oferecer oportunidades de desenvolvimento das capacidades ao aluno com deficiência física e/ou intelectual deve ser um compromisso da escola para com esses indivíduos, respeitando seus limites e criando novas formas de ensinar.

Conforme as Diretrizes Curriculares Nacionais para o Ensino Fundamental (BRASIL, 2010, p. 9), "a escola comum se torna inclusiva quando reconhece as diferenças dos alunos diante do processo educativo e busca a participação e o progresso de todos, adotando novas 
práticas pedagógicas". Portanto, a escola cumpre seu dever social quando prepara seu ambiente e sua equipe de maneira a permitir que seus alunos possam ampliar seus conhecimentos e sua visão de mundo.

\section{A UTILIZAÇÃO DO AMBIENTE VIRTUAL MOODLE NO ENSINO DA MATEMÁTICA}

A tecnologia faz parte da nossa vida cotidiana. Ela está direta ou indiretamente presente na maioria de nossas tarefas, mas foi com o avanço da ciência que o ser humano evoluiu, utilizando-se de um conhecimento que levou o indivíduo ao mundo virtual, global e sincronizado. $\mathrm{Na}$ área educacional, ela vem sendo constantemente usada por meio de diversas ferramentas que fazem parte do dia a dia escolar como, por exemplo, uso de programas de TV, filmes, propagandas, jornais, revistas e, claro, a internet e os softwares.

O ambiente virtual de aprendizagem vem se difundindo no decorrer dos anos, principalmente com a modalidade de ensino a distância $(\mathrm{EaD})$, integrando o conhecimento à vida de muitos indivíduos que antes não tinham a oportunidade de acesso ao estudo e à informação. Segundo Silva (2013, p.12), “os ambientes virtuais de ensino e aprendizagem são os que mais crescem em qualidade e adesão social no cenário, também crescente, da educação na modalidade online".

Martiniano (2015, p. 18) afirma que “a educação a distância está modificando as formas de ensinar e aprender, inclusive as presenciais, que começam a utilizar cada vez mais metodologias semipresenciais, reorganizando os espaços, tempo, mídias, linguagens e processos" (apud MORAN, 2013, p. 63). Portanto, é fundamental utilizar as ferramentas tecnológicas, como os ambientes virtuais de ensino e aprendizagem, que se mostram eficientes na construção do conhecimento.

Segundo a associação de professores de Matemática dos Estados Unidos (NCTM), "a tecnologia é essencial no ensino e na aprendizagem da Matemática" e "influencia a Matemática que é ensinada e melhora a aprendizagem dos alunos”, possibilitando que estes se centralizem "nas decisões a tomar, na reflexão, no raciocínio e na resolução de problemas" (NCTM, 2007, p. 26).

Quando falamos de tecnologia como ferramenta de aprendizagem da Matemática, podemos retornar à década de 1960, quando os computadores ainda eram raros e dispendiosos. O Ensino Assistido por Computador (EAC), conforme Carvalho (2013), consistia em programas de repetição e treino (drill and practice), constituídos por folhas eletrônicas de 
exercícios, nos quais os alunos eram induzidos a seguir os comandos dos computadores de maneira mecânica. Mais tarde surgiu o LOGO, uma linguagem de programação desenvolvida pelo MIT (Instituto de Tecnologia de Massachussets) por Seymour Papert e Wallace Feurzig. Essa ferramenta teve o objetivo de reproduzir um ambiente interativo em que "quando se manda executar uma primitiva ou um procedimento obtém-se imediatamente feedback, o que permite aos alunos autocorrigirem-se, sendo o erro encarado como uma forma de aprendizagem e não como algo penalizador" (CARVALHO, 2013, p. 22).

Com a expansão da internet a partir dos anos 1990, a educação matemática angariou diversos aliados tecnológicos na construção do conhecimento. Ponte et al (2003) e Duarte et al (2008) apud Carvalho (2013, p. 27), descreve alguns recursos:

- materiais educativos disponíveis para o ensino da Matemática, incluindo planos de aula, problemas e possíveis investigações, desafios, simples curiosidades, informação de natureza científica, materiais didáticos como software específico de livre distribuição, tais como o GeoGebra (um AGD), exemplos de tarefas para aplicar nas aulas, descrição de experiências, jogos didáticos e outros recursos que podem ser acedidos e explorados online, como é o caso das applets (aplicações interativas que abordam tópicos específicos de Matemática) (Ponte et al., 2003; Duarte et al., 2008);

- espaços de publicação, de comunicação, de colaboração na construção de conhecimento e de suporte à criação de pequenas comunidades virtuais, como as plataformas de gestão da aprendizagem (Duarte et al., 2008).

O ambiente virtual de aprendizagem atualmente é um recurso tecnológico que vem se destacando. Neste artigo, definiremos o ambiente virtual de aprendizagem (AVA), conforme Vavassorib e Raabe (2003), como uma reunião de recursos e ferramentas que possibilitam e intensificam a sua utilização em atividades de aprendizagem através da internet, presencialmente ou à distância.

O conceito do ambiente de aprendizagem tem como essência a ideia de "aprender a aprender", a qual se caracteriza pelo aprendizado construído ao longo da vida. Dessa forma, pretende-se envolver os alunos de forma prática, num contexto de aprendizagem favorável, com respeito pelas diferenças individuais, abrangendo trabalho em equipe, conhecimentos matemáticos e o aprender fazendo.

O Moodle (Modular Object-Oriented Dynamic Learning Environment) é um projeto desenvolvido por Martin Dougiamas, na Austrália em 1999. Esse software está entre os ambientes virtuais mais populares do mundo e destaca-se por valorizar a aprendizagem colaborativa. Conforme Souza (2013), uma das principais características do Moodle é ser livre, permitindo a qualquer indivíduo integrar, discutir, interagir e modificar frequentemente, contribuindo para o desenvolvimento do ambiente. A adesão de uma aprendizagem baseada em uma "pedagogia social construcionista" também é outro fator que chama atenção dos usuários. 
A plataforma possui ferramentas interativas como os fóruns, chats, questionários, tarefas, lições, entre outras. Tais ferramentas colaboram para um ensino e aprendizagem focada na construção da autonomia do aluno através desse compartilhamento de conhecimentos.

\section{METODOLOGIA E DESCRIÇÃO DAS ATIVIDADES}

O desenvolvimento desse trabalho se deu, a princípio, com pesquisas bibliográficas em artigos científicos e trabalhos acadêmicos, objetivando à fundamentação do assunto e aprofundamento dos conhecimentos e conceitos acerca do tema.

As autoras basearam-se, principalmente, na experiência de Zwan (2016), a qual se caracteriza por investigar os conhecimentos de alunos surdos acerca dos recursos tecnológicos e utilizar o Moodle a fim de propor um curso, para esses alunos, que aborda o conteúdo de Matrizes.

Para a elaboração dessa pesquisa, utilizou-se abordagem qualitativa, na qual os alunos realizaram atividades no Ambiente Virtual de Aprendizagem (AVA) e posteriormente responderam a um questionário onde apontaram suas percepções a respeito da experiência. $\mathrm{O}$ questionário contou com 10 (dez) perguntas de múltipla escolha e discursivas, para que os alunos pudessem expressar-se sobre todo o itinerário de realização das atividades.

O público-alvo da pesquisa foram alunos dos anos finais do Ensino Fundamental que apresentavam deficiência auditiva, déficit cognitivo, transtorno do déficit de atenção e hiperatividade (TDAH), transtorno desafiador de oposição (TOD), distúrbios na coordenação motora, autismo e paralisia cerebral.

As atividades tiveram início no mês de fevereiro, logo quando as aulas se iniciaram. Participaram dessa pesquisa duas escolas públicas, uma da cidade de Arcos (MG) e outra da cidade de Cláudio (MG).

A clientela das escolas varia de alunos de classe média a alunos em situação de vulnerabilidade social. As duas escolas apresentam ambiente físico harmônico (ambiente limpo e conservado), apesar de não contarem com acessibilidade e disporem de poucos recursos que auxiliam na aprendizagem de alunos com deficiência.

Na cidade de Arcos (MG), foram observados sete alunos, sendo eles: 6 alunos do $6^{\circ}$ ano, dos quais 4 apresentam transtorno do déficit de atenção e hiperatividade (TDAH), 1 com autismo e 1 com paralisia cerebral, e uma aluna surda do $7^{\circ}$ ano. Na escola dessa cidade, há a Sala de Recursos Multifuncionais, portanto, todas as atividades foram realizadas extraclasse, com o suporte da intérprete de libras e da professora de Atendimento Educacional Especializado 
(AEE).

$\mathrm{Na}$ cidade de Cláudio (MG), foram observados três alunos do $7^{\circ}$ ano do Ensino Fundamental que possuem déficit cognitivo, transtorno do déficit de atenção e hiperatividade (TDAH), transtorno desafiador de oposição (TOD), distúrbios na coordenação motora e paralisia cerebral. A escola não possui Sala de Recursos Multifuncionais, mas os alunos podem frequentar a sala em outra escola estadual da cidade, no contraturno do ensino regular. Neste caso, os alunos realizaram as atividades juntos e foram observadas as interações com as atividades e entre eles. A professora de Atendimento Educacional Especializado (AEE) também ofereceu suporte, principalmente em relação ao direcionamento das atividades, já que esses alunos apresentaram resistência antes mesmo de conhecer a proposta de trabalho.

É importante ressaltar neste artigo a importância dos profissionais de Atendimento Educacional Especializado (AEE), uma vez que esses professores apresentam um conhecimento que, muitas vezes, professores do ensino regular não têm e acabam por excluir os alunos com deficiência dentro da sala de aula. É visto que nesse tipo de atendimento os professores não só ensinam a valorizar as habilidades cognitivas de um aluno com deficiência, mas também trabalham as relações sociais, como comportamento, independência e hábitos. Além disso, as professoras de AEE produzem e investem em materiais que possibilitam a aprendizagem de cada aluno. Percebemos o quanto elas também viram as oportunidades de ensinar e aprender através da plataforma Moodle.

Para criação da sala virtual, contou-se com o apoio docente do Dr. Niltom Vieira Júnior, professor do curso de Pós-Graduação em Docência ofertado pelo Instituto Federal de Minas Gerais- Campus Arcos. Ele criou a sala destinada aos alunos, enquanto as autoras forneceram todo conteúdo da sala.

Buscando atender os critérios que zelam pelos direitos e dignidade dos sujeitos da pesquisa, as atividades e o questionário foram submetidos à avaliação do Instituto Federal de Minas Gerais- Campus Arcos e também à equipe diretiva e supervisora das duas escolas participantes, que concordaram com a pertinência e relevância do trabalho proposto.

Primeiramente, apresentamos o Ambiente Virtual de Aprendizagem do MOODLE para os alunos, mostrando as potencialidades e os recursos oferecidos por ele e destacamos também a importância da plataforma como um novo recurso de ensino na Matemática. Em seguida, mostramos as atividades propostas que seriam feitas durante o semestre. 


\section{PESQUISA 01 \\ Bariasinicial / Meuscarsos / baer}

SEJA BEM VINDO!

Seuprogrewio 0

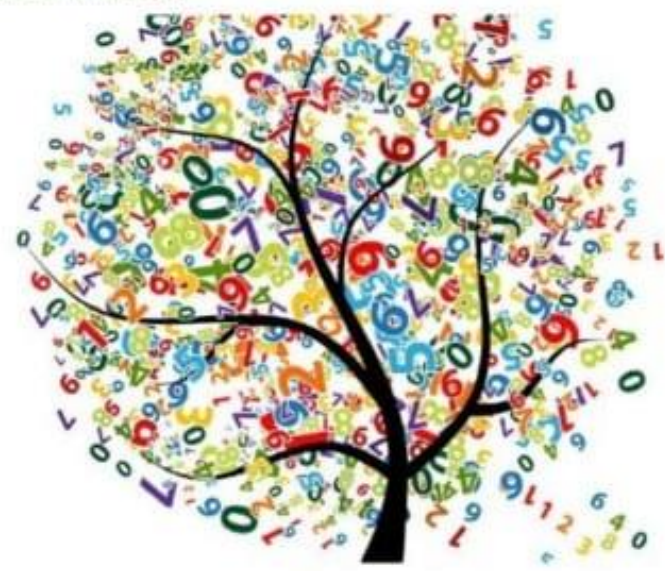

SALA DESTINADA AOS ALUNOS DA SALA DE RECURSOS AQUI SERR̃O DISPONIEIUZADOS EXERCICOS EJOCOS SOARE OS CONTEÚDOS DE MATEMATICA.

FACA COM ATENCT̄O E BOM TRABALHO!

DALANEE SUYARA

W Avises

\section{OPERAÇŌES FUNDAMENTAIS}

a. Tabuada do Dirio

RESOLUÇĀO DE PROBLEMAS ENVOLVENDO AS 4 OPERAÇŌES FUNDAMENTAIS
$\checkmark$ Pesoluciode Problemasemoliendo Adiclio
$\checkmark$ Pesolucàe de Problemasemolrendo Subtracào
$\nabla$ sesolucio de Probliemasemolendo Multialicacic
$\checkmark$ Aesoluçăo de Problemasenvolvendo Divisato

\section{CEOMETRIA PLANA E ESPACIAL \\ Fis lona farma centencicas \\ $\nabla$ eOrmasceométricas}

\section{UNIDADES DEMEDIDA}

풀 Aprendendo as horas

Ëen CALENDARIO Mácico

\section{EQUAÇŌES DO $1^{\circ}$ \\ 토 Quizequacho do primeirogras}

Figura 1 - Sala virtual

Fonte: https://ead.ifmg.edu.br/arcos/course/view.php?id=54 
Na sala, foram disponibilizadas atividades simples de matemática básica, tendo em vista o comprometimento cognitivo de 9 dos 10 alunos monitorados. Foram criadas seções que exploram quatro temas: Operações Fundamentais, Geometria Plana e Espacial, Unidades de Medida e Equação do $1^{\mathrm{o}}$ grau. As tarefas foram realizadas uma vez por semana e com grupos de três alunos para que as autoras pudessem acompanhar o desempenho de cada discente e fazer as devidas intervenções, quando necessário. Solicitamos aos alunos que fizessem o registro dos raciocínios para uma análise mais detalhada das questões resolvidas.

As atividades foram disponibilizadas no site https:/ead.ifmg.edu.br/arcos/ e qualquer pessoa pode ter acesso, criando um usuário e login na página. As tarefas consistem em jogos educativos, hospedados em diversos sites da internet (na sala, foram criados links que redirecionam para os jogos com apenas um clique); questionários com perguntas de múltiplas escolhas e que buscam relacionar situações do cotidiano do aluno com a Matemática. Todas as tarefas não tinham como objetivo introduzir algum conceito novo, mas fixar os conteúdos já estudados no ensino regular.

Os recursos do Moodle utilizados pelas autoras foram a lição, que publica o conteúdo de maneira flexível e, por isso, não precisa ser construído na plataforma, mas pode direcionar para atividades de outros sites, e o questionário, recurso que oferece inúmeras possibilidades de formatos de questões para compor a avaliação das atividades, sendo eles: múltipla escolha, verdadeiro ou falso, resposta breve, numérica, dissertativa, entre outras. As questões são armazenadas formando um banco de questões que podem ser inseridas em quaisquer questionários elaborados pelo professor. Uma vantagem do questionário é que a correção das questões é feita pelo próprio sistema, exceção feita às questões dissertativas que são corrigidas pelo próprio professor.

\section{ANÁLISES E RESULTADOS}

A principal motivação para se desenvolver este trabalho foi experimentar novas estratégias didáticas com alunos com deficiência, usando algo inovador e dinâmico.

Os resultados foram obtidos de forma qualitativa a partir da observação e análise das autoras na realização das atividades, no registro feito pelos alunos no decorrer das mesmas e na análise do questionário respondido após a realização das tarefas.

Para essa análise, conforme já ressaltamos, foi utilizada a experiência de Zwan (2016) em relação ao uso do Ambiente Virtual de Aprendizagem (AVA) na plataforma Moodle no aprendizado de alunos com deficiência. Os pontos para reflexão foram: Como os alunos lidaram 
com o Ambiente Virtual de Aprendizagem? O que chamou a atenção nesse ambiente? A proposta foi de fácil entendimento? As atividades são inclusivas para alunos com deficiência? Quanto à aprendizagem, essas atividades auxiliaram no processo de aprendizagem de matemática? As dificuldades puderam ser contornadas? Quais benefícios as atividades apresentaram? A proposta de implementação de atividades e a utilização do AVA é importante?

As respostas para essas reflexões foram retiradas, principalmente, do questionário respondido pelos alunos após a realização das atividades. Alguns alunos ainda não eram alfabetizados e por isso responderam o questionário oralmente.
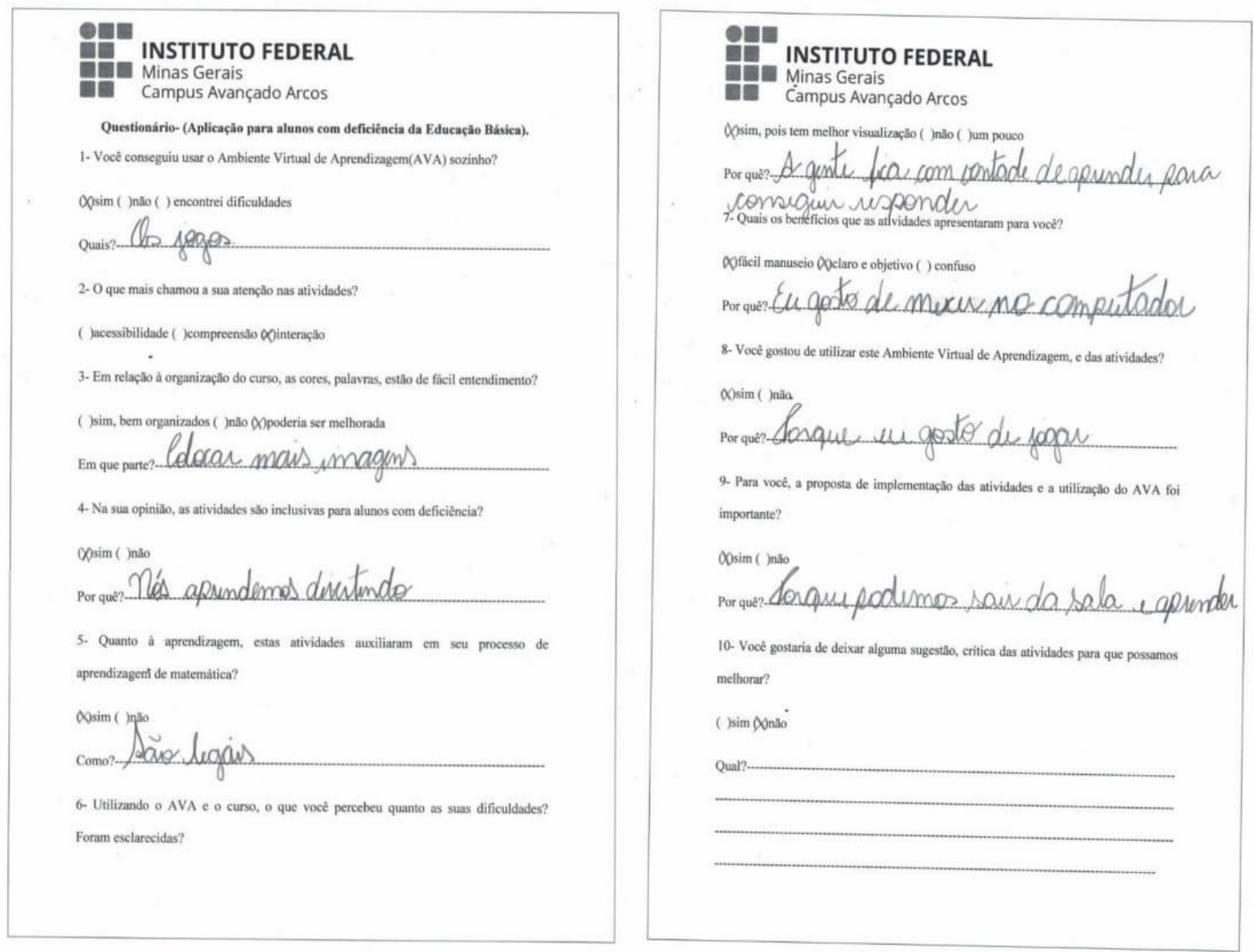

Figura 2 - Questionário Fonte: Próprias autoras.

Sobre a utilização do Ambiente Virtual de Aprendizagem, apenas um aluno necessitou de atenção maior para acessar as tarefas. Nove alunos conseguiram acessar livremente os jogos, pois conforme citado, eles já estavam acostumados a acessar plataformas de jogos online como o clickjogos.com, poki.com e jogos360.com.br. A propósito, as professoras de AEE apontaram que utilizam essa estratégia como forma de recompensar quando os alunos realizam uma atividade em sala de aula a que tenham alguma resistência. 
Em relação ao que chamou a atenção dos alunos, obtivemos como respostas as animações e as cores. Percebemos que o ambiente tornou o aluno interativo e concentrado devido a esses fatores.

Os jogos foram as atividades mais motivadoras e os alunos foram bem-sucedidos nas tarefas propostas com esse recurso. Já nos questionários com resolução de problemas, os alunos precisaram de ajuda, não por causa do recurso, mas pela necessidade de contextualizar as questões. De acordo com os feedbacks, poderiam ser adicionadas imagens como forma de sanar a dificuldade de interpretação que a maioria dos alunos apresentou.

Durante a realização das atividades, surgiram algumas dúvidas como, por exemplo, se conseguiríamos nos comunicar com a aluna surda, mas fomos auxiliadas pela intérprete de Libras que repassava a ela todas as nossas orientações. A aluna realizou com sucesso as atividades, demonstrando domínio no manuseio do computador e em atividades de interpretação com problemas envolvendo as operações fundamentais.

De fato, é notável a dificuldade dos alunos (inclusive do ensino regular) em compreender a matemática algébrica e percebemos que as atividades de equação do $1^{\circ}$ grau disponíveis na plataforma devem ainda ser adaptadas para melhor atender as necessidades dos alunos de maneira geral, com ou sem deficiência.

Todavia, percebemos muitas mudanças no comportamento dos alunos participantes da experiência dentro da sala de aula. A motivação, autoconfiança, vontade de participar mais das aulas de Matemática foram algumas delas. Dois dos alunos participantes da experiência na escola de Cláudio foram premiados pela professora do ensino regular em uma prova sobre geometria porque tiraram nota máxima. Este resultado demonstra como as atividades dinâmicas da plataforma atuaram como propulsores para o aprendizado desses alunos.

A produtividade deles também foi um fator significante. Mesmo com as limitações, notamos que, quando há adaptação e atenção, os alunos conseguem se desenvolver e se mantêm motivados a buscar o conhecimento.

\section{CONSIDERAÇÕES}

O presente trabalho mostrou que o processo de inclusão de pessoas com deficiências em escolas regulares tem evoluído significativamente nos últimos anos. Isso só foi possível a partir da criação de leis de inclusão que permitiram o acesso desses alunos às escolas regulares de ensino. Essas leis asseguram uma educação de qualidade para esses indivíduos. 
Dessa ótica, verifica-se a importância que a tecnologia desempenha nos processos de inclusão dos alunos com deficiência no contexto educacional. A aplicação dos recursos tecnológicos na escola auxilia no desenvolvimento do processo de aprendizagem.

A utilização do Ambiente Virtual de Aprendizagem tem crescido significativamente, apresentando ganhos com o uso de recursos que contribuem para a garantia do ensino de boa qualidade. Logo, o objetivo de utilizar a plataforma Moodle para se reforçar os conteúdos matemáticos para alunos com deficiência foi alcançado.

Reconhecer que a tecnologia já está presente na vida de qualquer pessoa é necessário para que os profissionais da educação, em suas diversas funções, utilizem esse recurso de maneira a agregar conhecimento e despertar o interesse daqueles que mais necessitam de meios estratégicos e diferenciados para se alcançar o aprendizado.

Dentre todas as contribuições que esta pesquisa trouxe, podemos ressaltar maior motivação e envolvimento dos alunos nas aulas e na realização das atividades propostas. É visto que atividades na plataforma Moodle, principalmente jogos com bastante animação e interação com o jogador, aguçam o desejo de aprender para então realizar com êxito as atividades.

O momento de interação foi essencial para o crescimento pessoal e profissional das autoras. Acompanhar esses alunos de perto mostrou que cada aluno tem o seu tempo para aprender e que é preciso valorizá-lo por cada passo avançado.

\section{REFERÊNCIAS}

ALVES, D. O. Sala de recursos multifuncionais: espaços para atendimento educacional especializado. Brasília: 2006. Disponível em: http://www.oneesp.ufscar.br/orientacoes_srm_2006.pdf. Acesso em: 24 jan. 2019.

BRASIL. Lei n. 7853, de 24 de outubro de 1989. Dispõe sobre o apoio às pessoas portadoras de deficiência, sua integração social, sobre a Coordenadoria Nacional para Integração da Pessoa Portadora de Deficiência. Brasília: 1989. Disponível em: http://www.planalto.gov.br/ccivil_03/leis/17853.htm. Acesso em: 10 jan. 2019.

BRASIL. Ministério da Educação. Conselho Nacional De Educação. Câmara De Educação Básica. Diretrizes Curriculares Nacionais para o Ensino Fundamental de 9 (nove) anos. Brasília: 2010. Disponível em: http://portal.mec.gov.br/dmdocuments/rceb007_10.pdf. Acesso em: 10 jan. 2019.

BRASIL. Saberes e práticas de inclusão: desenvolvendo competências para o atendimento às necessidades educacionais de alunos com deficiência física/ neuro-motora. Brasília: MEC/ SEESP, 2006. Disponível em: http://portal.mec.gov.br/seesp/arquivos/pdf/alunosdeficienciafisica.pdf. Acesso em: 10 jan. 2019. 
CARMO, E. T. Importância dos jogos como metodologia da educação inclusiva na Escola Municipal Morro Encantado Em Cavalcante Goiás. Programa de Pós-Graduação em Processos de Desenvolvimento Humano e Saúde - PGPDS. Universidade de Brasília. Brasília- DF, 2015. Disponível em:

http://bdm.unb.br/bitstream/10483/15568/1/2015_ElidianeTorresDoCarmo_tcc.pdf. Acesso em: 24 jan. 2019.

CARVAlHO, L. T. Ambiente Virtual de Aprendizagem Matemática em contexto educativo. Dissertação. Universidade de Lisboa, 2013. Disponível em:

https://repositorio.ul.pt/bitstream/10451/10336/1/ulfpie046329_tm.pdf. Acesso em: 15 dez. 2018.

HONORA, M.; FRIZANCO, M. E. Esclarecendo as deficiências: aspectos teóricos e práticos para contribuição com a sociedade inclusiva. São Paulo, SP: 2008.

MARTINS, C. A. O ambiente virtual de aprendizagem MOODLE-UFBA como veículo de difusão do conhecimento. Monografia. Universidade Federal da Bahia, Instituto de Matemática Departamento de Ciência da Computação, Salvador, 2009, 44 f. Disponível em: <http://www.pucrs.br/ciencias/viali/mestrado/literatura/monografias/Monografia_Claudio_Ma rtins_Moodle.pdf>. Acesso em: 17 mar. 2020.

MARTINIANO, E. Um estudo sobre a utilização da plataforma moodle no processo de ensino e aprendizagem de biologia. Dissertação. Universidade Federal do Paraná, Londrina, 2015, 101 f. Disponível em: <http://repositorio.utfpr.edu.br/jspui/bitstream/1/1393/1/LD_PPGEN_M_Martiniano\%2C\%20 Eziquiel_2015.pdf >. Acesso em: $15 \mathrm{de}$ dez de 2018.

NCTM. Princípios e normas para a matemática escolar. (M. Rebelo, Trad.) Lisboa: 2007. APM.

VAVASSORIB, F; RAABE, A. Organização de atividades de aprendizagem utilizando ambientes virtuais: um estudo de caso. In: M. Silva (Ed.), A educação online (pp. 311-326). São Paulo: Loyola. 2003.

SILVA, R. S. Moodle 2 para autores e tutores. 3.ed. São Paulo: Novatec, 2013.

SOUZA, C. A. Análise do Moodle como ferramenta de aprendizagem para os alunos do curso de licenciatura em informática do Polo de Missão Velha/CE. Monografia.

Universidade Estadual do Ceará, Centro de Ciências e Tecnologia, Vila Velha, 2013, 59 f. Disponível em: http://www.uece.br/computacaoead/index.php/downloads/doc_view/2033tccciceradealencar?tmpl=component\&format=raw. Acesso em: 10 jan. 2019.

ZWAN, L. D. Ambiente virtual inclusivo para o ensino de matemática para alunos surdos da educação básica. Santo Ângelo: URI, 2016. Disponível em: https:/educapes.capes.gov.br/bitstream/capes/205003/2/dissertacao\%20liciara.PDF. Acesso em: 17 mar. 2020.

Submetido em: 04 de dezembro de 2019 . Aprovado em: 15 de março de 2020. 